\title{
A new attribute sampling plan using neutrosophic statistical interval method
}

\author{
Muhammad Aslam ${ }^{1}$ (D)
}

Received: 11 November 2018 / Accepted: 18 December 2018 / Published online: 3 January 2019

(c) The Author(s) 2019

\begin{abstract}
In the classical statistics, for the inspection of a final lot of the product, a decision is made either the lot has good quality or not using an acceptance sampling plan. The acceptance of sampling using the classical statistics assumes that data are determinate. In some situations, the data may imprecise and even intermediate which leads to indecision about the quality of the submitted lot of the product. In this situation, neutrosophic statistics can be applied for the lot sentencing. In this paper, a new attribute sampling plan is proposed using the neutrosophic interval method. The lot acceptance, rejection, and indeterminate probabilities are computed using the neutrosophic binomial distribution at various specified parameters such as sample size and acceptance number. The efficiency of the proposed sampling plan is also discussed. A real example is also added to explain the proposed sampling plan.
\end{abstract}

Keywords Statistics $\cdot$ Neutrosophic $\cdot$ Distribution $\cdot$ Lot

\section{Introduction}

To achieve the high quality of the product, an inspection of the product from raw material to the final product is an essential part of the manufacturing process. The inspection of a lot of the product through the sampling plan ensures not accepting the bad lot or rejecting a good lot of the product. For the final submitted lot of the product, the supplier is often interested to know the lot acceptance probability. In the traditional acceptance sampling plan, a random sample from a lot of the product is selected and inspected for the purpose of the lot sentencing. A lot of the product is either rejected or accepted on the basis of sample information. The decision of acceptance or rejection is made under the assumption that there is no indeterminate in the data. More details about the attribute sampling plan using the traditional/classical statistics can be seen in [1].

In practice, it may possible that sample information is incomplete, complex, imprecise and indeterminate to make a decision about the lot sentencing. In this situation, the decision about a lot of the product is not binary that is either accept

Muhammad Aslam

aslam_ravian@hotmail.com

1 Department of Statistics, Faculty of Science, King Abdulaziz University, Jeddah 21551, Saudi Arabia or reject a lot of the product. So, we cannot apply the crisp values to make a decision such as in classical statistics. For an example, from a lot of watches, a random sample is selected and their display type is noted. It is found that $90 \%$ watches have a proper display, $10 \%$ have no display and about $10 \%$ no evidence about the type of watches. In this case, there is some indeterminacy probability which invites to use the acceptance plan using the neutrosophic statistics.

The traditional sampling plans are applied when the experimenter or the producer is certain about the proportion parameter. So, the sampling plans having the assumption of determined value cannot be applied when there is uncertainty or indeterminacy about proportion parameter. The fuzzy sampling plans have been widely applied for the lot sentencing when there is uncertainty in the proportion parameter. Several authors contributed to designing the sampling plan using the fuzzy approach, see for example, Cheng et al. [2] proposed a fuzzy testing process to select a better process. Jamkhaneh et al. [3] studied the effect of inspection error using the single sampling plan. Sadeghpour Gildeh et al. [4] and Jamkhaneh and Gildeh [5] designed double sampling plan under the fuzzy approach. Turanoğlu et al. [6] studied the characteristic curve of the sampling plan. Jamkhaneh and Gildeh [7] proposed the fuzzy sequential sampling plan. Divya [8] worked on a single sampling plan using the Poisson distribution. Venkateh and Elango [9] designed sampling plan for fuzzy

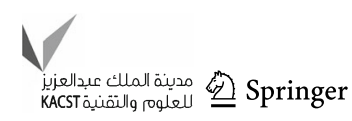


gamma distribution. Kahraman et al. [10] designed the single and double sampling plans under the fuzzy approach. Afshari and Gildeh [11], Afshari et al. [12, 13] designed fuzzy plans using multiple dependent state sampling. Elango et al. [14] developed the fuzzy mathematics for the single sampling plan.

Recently, the neutrosophic logic attracts the researches due to the flexibility of dealing the indeterminacy in the observations and the proportion parameter. Smarandache [15] argued that the neutrosophic logic is the generalization of the fuzzy logic. According to [16] "a new emerging tool for uncertain data processing which is known as neutrosophic sets. A neutrosophic set has the potentiality of being a general framework for uncertainty analysis in data sets". According to [17] "The single valued neutrosophic set is a generalization of classic set, fuzzy set, interval valued fuzzy set, intuitionistic fuzzy set, and paraconsistent set". According to [18] "Neutrosophic sets are powerful logics designed to facilitate understanding of indeterminate and inconsistent information; many types of incomplete or complete information can be expressed as interval valued neutrosophic sets (IVNSs)". Based on the neutrosophic logic, [19] introduced the neutrosophic statistics (NS). The NS is the generalization of the classical statistics which can be applied to analyze the data under uncertainty environment. Chen et al. [20, 21] studied rock measuring problems using the neutrosophic interval method. More details about the neutrosophic application can be seen in [22-31]. Recently, [32] introduced the NS in the area of acceptance sampling plan first time. Aslam and Arif [33] designed the sudden death test using the NS. Aslam and Raza [34] proposed the plan for multiple manufacturing lines using the NS. Aslam [35] proposed the plan for the exponential distribution using the NS. More applications of the NS can be read in [36-40].

By exploring the literature and best of author knowledge, there is no work on the design of attribute acceptance sampling plan using the neutrosophic statistics. Therefore, in this paper, we will focus to design an attribute sampling plan using neutrosophic statistics. In this paper, a new attribute sampling plan is proposed using neutrosophic statistics. The operational procedure of the proposed sampling plan is given. The lot acceptance, rejection, and indeterminate probabilities are computed using the neutrosophic binomial distribution at various specified parameters such as sample size and acceptance number. We expect that the proposed sampling plan will be more adequate, effective, flexible and information than the existing sampling plan under the uncertainty environment.

\section{Design of the proposed plan}

The existing attribute sampling plan under the classical statistics provides the two possible outcomes about the submitted lot of the product. A lot of the product is accepted if the number of failures is smaller than the specified number of failures $c$, otherwise, the lot of the product is rejected. In real industry, there some situations when the experimenter is uncertain either the product should be labeled as defective or good. In the case of uncertainty, the existing sampling plan can be applied for the inspection of a lot of the product. In this section, we will discuss and propose the sampling plan under the uncertainty environment.

Let $X$ is the quality of interest, $x^{\mathrm{L}}$ and $x^{\mathrm{U}}$ are the minimum value and maximum value of the data. Suppose that $a=\left[x^{\mathrm{L}}, x^{\mathrm{U}}\right]$ be the required range for the sample data. The neutrosophic interval probability (NIP) based on $x^{\mathrm{L}}$ and $x^{\mathrm{U}}$ is $p=\left\langle\left[x^{\mathrm{L}}, x^{\mathrm{U}}\right], \quad\left(p_{\mathrm{ND}}, p_{\mathrm{I}}, p_{\mathrm{D}}\right)\right\rangle$. Note that $p_{\mathrm{ND}}, p_{\mathrm{I}}$ and $p_{\mathrm{D}}$ denote non-defective probability belong to determine part, indeterminacy probability belong to an intermediatedefective part and falsity-probability belong to failure range of interval $p \leq\left[x^{\mathrm{L}}, x^{\mathrm{U}}\right],\left(p_{\mathrm{ND}}, p_{\mathrm{I}}, p_{\mathrm{D}}\right)$, respectively. The total probability for the three cases satisfies $p_{\mathrm{ND}}+p_{\mathrm{I}}+p_{\mathrm{D}} \geq$ 1.

The proposed sampling plan using neutrosophic statistics is stated as follows

Step-1: Select a random sample of size $\mathrm{n}$ from a lot of the product and obtain $x^{\mathrm{L}}$ and $x^{\mathrm{U}}$.

Step-2: Compute mean $\bar{X}=\sum_{i=1}^{n} X_{i} / n$ and standard deviation (SD) as $\mathrm{SD}=\sqrt{\sum_{i=1}^{n}\left(X_{i}-X\right)^{2} / n-1}$.

Step-3: Set $a=\left[x^{\mathrm{L}}, x^{\mathrm{U}}\right]$ and compute the probability of non-defective items $p_{\mathrm{ND}}=n_{\mathrm{ND}} / n$, the indeterminate probability $p_{\mathrm{I}}=n_{\mathrm{I}} / n$ and the probability of an defective item $p_{\mathrm{D}}=n_{\mathrm{D}} / n$, where $n_{\mathrm{ND}}, n_{\mathrm{I}}$ and $n_{\mathrm{D}}$ is the number of values in non-failure interval $[\bar{X}-S, \bar{X}+S]$, indeterminate/uncertain interval $[\bar{X}-3 S, \bar{X}-S] ;[\bar{X}+S, \bar{X}+3 S]$ and incredible/failure interval $\left[x^{\mathrm{L}}, \bar{X}-3 S\right] ;\left[\bar{X}+3 S, x^{\mathrm{U}}\right]$, see for example [21].

Step-4: Accept a lot of the product if a number of defectives are smaller than the allowed number of defectives $c$, otherwise, reject the lot of the product.

The proposed sampling consists of two parameters which are the acceptance number $c$ and sample size $n$. The neutrosophic operating characteristics (NOC) function of the proposed plan using neutrosophic binomial distribution (NBD) [19] is given as follows

$L(p)=P_{\mathrm{R}}+P_{\mathrm{I}}+P_{\mathrm{A}} ; \quad p_{\mathrm{ND}}+p_{\mathrm{I}}+p_{\mathrm{D}} \geq 1$

where $P_{\mathrm{R}}, P_{\mathrm{I}}$ and $P_{\mathrm{A}}$ denote a lot rejection, intermediate and acceptance probabilities, respectively.

$P_{\mathrm{R}}=\frac{n !}{c !} P(R)^{c} \cdot \sum_{k=0}^{c} \frac{P(I)^{k} P(F)^{n-c-k}}{k !(n-c-k) !}, \quad P_{\mathrm{I}}=$
$\sum_{z=c+1}^{n} \frac{n !}{z !} P(I)^{z}\left[\sum_{k=0}^{c-z} \frac{P(R)^{k} P(F)^{n-z-k}}{k !(n-z-k) !}\right]$ and $P_{\mathrm{A}}=$
$\sum_{y=c+1}^{n} T_{y}=\sum_{y=c+1}^{n} \frac{n !}{y !} P(I)^{y} \cdot\left[\sum_{k=0}^{n-y} \frac{P(R)^{k} P(F)^{n-y-k}}{k !(n-y-k) !}\right]$.
$\quad$ Note here that $P(R)=p_{\mathrm{ND}}, P(I)=p_{\mathrm{I}}$ and $P(A)=p_{\mathrm{D}} ;$ $p_{\mathrm{ND}}+p_{\mathrm{I}}+p_{\mathrm{D}} \geq 1$. 
The lot acceptance probability is the set of the lot rejection probability, indeterminate probability, and lot acceptance probability is given by

$L(p)=\left\{P_{\mathrm{R}}, P_{\mathrm{I}}, P_{\mathrm{A}}\right\}$

The difference between, fuzzy statistics, neutrosophic statistics and classical statistics can be seen in the following table

\begin{tabular}{lll}
\hline Fuzzy statistics & $\begin{array}{l}\text { Neutrosophic } \\
\text { statistics (NS) }\end{array}$ & Classical statistics \\
\hline $\begin{array}{c}\text { The fuzzy statistics } \\
\text { is used to analyze } \\
\text { the uncertain data }\end{array}$ & $\begin{array}{l}\text { The NS is an } \\
\text { extension of the } \\
\text { fuzzy statistics } \\
\text { which deals with } \\
\text { uncertainty and } \\
\text { indeterminacy }\end{array}$ & $\begin{array}{c}\text { The classical } \\
\text { statistics cannot } \\
\text { be applied when } \\
\text { some observations } \\
\text { are indeterminate. }\end{array}$ \\
& $\begin{array}{l}\text { It is applied when } \\
\text { consists of } \\
\text { determined and }\end{array}$ & $\begin{array}{l}\text { all observations } \\
\text { are determined }\end{array}$ \\
& $\begin{array}{l}\text { undetermined } \\
\text { parts }\end{array}$ & \\
& $\begin{array}{l}\text { The NS binomial } \\
\text { distribution }\end{array}$ & The classical \\
provide the & binomial \\
distribution only & provides the \\
indeterminate, the & acceptance and \\
applied when the & acceptance and & rejection \\
proportion & the rejection & probabilities \\
parameter is fuzzy & probabilities & \\
&
\end{tabular}

In Tables 1 and 2, the lot rejection probability, lot rejection probability, indeterminate probability, and lot acceptance probability are presented for various values of $p_{\mathrm{ND}}, p_{\mathrm{I}}, p_{\mathrm{D}}$, and $c$. In Tables 1 and 2, some calculated probabilities may larger than one so the normalized vector of probabilities can be obtained for dividing each probability for their total. Similar tables can be made for any other values of specified parameters. A program is available from the author upon request. Table 1 is presented when $c=0,1,2$ and $p_{\mathrm{ND}}=$ $0.80, p_{\mathrm{I}}=0.20, p_{\mathrm{D}}=0.10$ and Table 2 is given when $c=0,1$, 2 and $p_{\mathrm{R}}=0.67, p_{\mathrm{I}}=0.27$ and $p_{\mathrm{D}}=0.03$. From Tables 1 and 2 , we note that the fixed value of $n$, the lot rejection probability, indeterminate probability, and lot acceptance probability increases as $c$ changes from 0 to 2 . Furthermore, for the fixed value of $c$, the lot rejection probability, indeterminate probability and lot acceptance probability decrease as $n$ increases. For example, when $c=0$, a lot acceptance probability is 0.1632 and it is 0.8935 when $c=2$. The indeterminate probability decreases as $c$ changes from 0 to 2 . For an example, when $c=0$, a lot indeterminate probability is 0.6333 and it is 0.0449 when $c=2$.

The following algorithm is used to find the probabilities about a lot of the product.
Table 1 The lot acceptance probabilities $L(p)=\left\{P_{\mathrm{R}}, P_{\mathrm{I}}, P_{\mathrm{A}}\right\}$ when $p_{\mathrm{ND}}=0.80, p_{\mathrm{I}}=0.20$ and $p_{\mathrm{D}}=0.10$

\begin{tabular}{llll}
\hline$n$ & $c=0$ & $c=1$ & $c=2$ \\
& $\left\{P_{\mathrm{R}}, P_{\mathrm{I}}, P_{\mathrm{A}}\right\}$ & $\left\{P_{\mathrm{R}}, P_{\mathrm{I}}, P_{\mathrm{A}}\right\}$ & $\left\{P_{\mathrm{R}}, P_{\mathrm{I}}, P_{\mathrm{A}}\right\}$ \\
\hline 5 & $\{0.2035,0.6333$, & $\{0.2543,0.2259$, & $\{0.0616,0.0449$, \\
& $0.1632\}$ & $0.5197\}$ & $0.8935\}$ \\
10 & $\{0.0414,0.8656$, & $\{0.1682,0.5668$, & $\{0.1383,0.2681$, \\
& $0.093\}$ & $0.2650\}$ & $0.5936\}$ \\
15 & $\{0.0084,0.9507$, & $\{0.0711,0.7864$, & $\{0.1261,0.5308$, \\
& $0.0409\}$ & $0.1425\}$ & $0.3430\}$ \\
20 & $\{0.0017,0.9819$, & $\{0.0246,0.9016$, & $\{0.0766,0.7320$, \\
& $0.0163\}$ & $0.0737\}$ & $0.1913\}$ \\
25 & $\{0.0003,0.9933$, & $\{0.0076,0.9566$, & $\{0.0369,0.8584$, \\
& $0.0063\}$ & $0.0358\}$ & $0.1047\}$ \\
30 & $\{0.00007$, & $\{0.0022,0.9814$, & $\{0.0152,0.9292$, \\
& $0.9976,0.0023\}$ & $0.0164\}$ & $0.0556\}$ \\
35 & $\{0.00001$, & $\{0.0006,0.9922$, & $\{0.0057,0.9660$, \\
& $0.9991,0.0009\}$ & $0.0072\}$ & $0.0283\}$ \\
40 & $\{0.000003$, & $\{0.0001,0.9968$, & $\{0.0019,0.9841$, \\
& $0.9997,0.0003\}$ & $0.0031\}$ & $0.0139\}$ \\
45 & $\{0.0000,0.9999$, & $\{0.00004$, & $\{0.0006,0.9928$, \\
& $0.0001\}$ & $0.9987,0.0013\}$ & $0.0065\}$ \\
50 & $\{0.0000,0.99995$, & $\{0.00001$, & $\{0.0001,0.9968$, \\
& $0.00005\}$ & $0.9995,0.0005\}$ & $0.0030\}$ \\
55 & $\{0.0000,0.99998$, & $\{0.000002$, & $\{0.00006,0.9986$, \\
& $0.00002\}$ & $0.9998,0.0002\}$ & $0.0013\}$ \\
\hline \multirow{2}{*}{5} & & &
\end{tabular}

Table 2 The lot acceptance probabilities $L(p)=\left\{P_{\mathrm{R}}, P_{\mathrm{I}}, P_{\mathrm{A}}\right\}$ when $p_{\mathrm{ND}}=0.67, p_{\mathrm{I}}=0.27$ and $p_{\mathrm{D}}=0.03$

\begin{tabular}{llll}
\hline$n$ & $c=0$ & $c=1$ & $c=2$ \\
& $\left\{P_{\mathrm{R}}, P_{\mathrm{I}}, P_{\mathrm{A}}\right\}$ & $\left\{P_{\mathrm{R}}, P_{\mathrm{I}}, P_{\mathrm{A}}\right\}$ & $\left\{P_{\mathrm{R}}, P_{\mathrm{I}}, P_{\mathrm{A}}\right\}$ \\
\hline 5 & $\{0.1419,0.8233$, & $\{0.0868,0.4572$, & $\{0.0081,0.1538$, \\
& $0.0348\}$ & $0.456\}$ & $0.8380\}$ \\
10 & $\{0.0201,0.9687$, & $\{0.0442,0.8394$, & $\{0.0176,0.5981$, \\
& $0.0111\}$ & $0.1164\}$ & $0.3842\}$ \\
15 & $\{0.0029,0.9945$, & $\{0.0136,0.9602$, & $\{0.0128,0.8607$, \\
& $0.0026\}$ & $0.0262\}$ & $0.1265\}$ \\
20 & $\{0.0004,0.9990$, & $\{0.0033,0.9909$, & $\{0.0058,0.9591$, \\
& $0.0005\}$ & $0.0057\}$ & $0.0351\}$ \\
25 & $\{0.00006,0.9998$, & $\{0.0007,0.9980$, & $\{0.0020,0.9892$, \\
& $0.0001\}$ & $0.0012\}$ & $0.0088\}$ \\
30 & $\{0.0000,0.99997$, & $\{0.0001,0.9996$, & $\{0.0006,0.9973$, \\
& $0.00002\}$ & $0.0003\}$ & $0.0021\}$ \\
35 & $\{0.0000,0.99999$, & $\{0.00003,0.9999$, & $\{0.0001,0.9994$, \\
& $0.000004\}$ & $0.00005\}$ & $0.0005\}$ \\
40 & $\{0.0000$, & $\{0.0000,0.99998$, & $\{0.00004$, \\
& $1.0000,0.0000\}$ & $0.00001\}$ & 0.99985, \\
& & & $0.0001\}$ \\
45 & $\{0.0000$, & $\{0.0000$, & $\{0.0000,0.99997$, \\
& $1.0000,0.0000\}$ & $1.0000,0.0000\}$ & $0.00002\}$ \\
50 & $\{0.0000$, & $\{0.0000$, & $\{0.0000$, \\
& $1.0000,0.0000\}$ & $1.0000,0.0000\}$ & $1.0000,0.0000\}$ \\
55 & $\{0.0000$, & $\{0.0000$, & $\{0.0000$, \\
& $1.0000,0.0000\}$ & $1.0000,0.0000\}$ & $1.0000,0.0000\}$ \\
\hline & & &
\end{tabular}


Table 3 Comparison in the lot acceptance probabilities when $p_{\mathrm{ND}}=$ $0.80, p_{\mathrm{I}}=0.20$ and $p_{\mathrm{D}}=0.10$

\begin{tabular}{lll}
\hline$n$ & $\begin{array}{l}\text { Proposed plan } \\
c=0 \\
\left\{P_{\mathrm{R}}, P_{\mathrm{I}}, P_{\mathrm{A}}\right\}\end{array}$ & $\begin{array}{l}\text { Plan under classical statistics } \\
c=0 \\
\left\{P_{\mathrm{R}}, P_{\mathrm{I}}, P_{\mathrm{A}}\right\}\end{array}$ \\
\hline 5 & $\{0.2035,0.6333,0.1632\}$ & 0.5904 \\
10 & $\{0.0414,0.8656,0.093\}$ & 0.3486 \\
15 & $\{0.0084,0.9507,0.0409\}$ & 0.2058 \\
20 & $\{0.0017,0.9819,0.0163\}$ & 0.1215 \\
25 & $\{0.0003,0.9933,0.0063\}$ & 0.0717 \\
30 & $\{0.00007,0.9976,0.0023\}$ & 0.0423 \\
35 & $\{0.00001,0.9991,0.0009\}$ & 0.0250 \\
40 & $\{0.000003,0.9997,0.0003\}$ & 0.0147 \\
45 & $\{0.0000,0.9999,0.0001\}$ & 0.0087 \\
50 & $\{0.0000,0.99995,0.00005\}$ & 0.0051 \\
55 & $\{0.0000,0.99998,0.00002\}$ & 0.0030 \\
\hline
\end{tabular}

1. Specify the acceptance number $c$ and sample size $n$.

2. Determine $p_{\mathrm{ND}}, p_{\mathrm{I}}$ and $p_{\mathrm{D}}$ using step-2.

3. Find $L(p)=\left\{P_{\mathrm{R}}, P_{\mathrm{I}}, P_{\mathrm{A}}\right\}$ using Eq. (2).

\section{Comparative study}

In this section, we will compare the proposed plan designed under the neutrosophic binomial distribution with the existing sampling plan designed under the classical binomial distribution in terms of probabilities of acceptance, rejection, and indeterminate. According to [21], a method which provides the outcomes in the interval rather than the determined values under the uncertainty environment is called the most effective method. We will select the same values of all parameters for both sampling plans. We preened the probabilities in Table 3 when $p_{\mathrm{ND}}=0.80, p_{\mathrm{I}}=0.20, p_{\mathrm{D}}=0.10$ and $c=0$.

From Table 3, it can be noted that the existing sampling plan under the classical statistics method provides the determined values at all specified parameters. On the other hand, the proposed plan under the neutrosophic interval method provides the probabilities in the interval. For an example, when $n=5$, the lot acceptance probability is 0.1632 , the probability of indeterminacy (i.e., neither an acceptance not a reject) is 0.6333 . It means, that when a lot of inspection with $n=5$ and $c=0$ is applied for the inspection of the lot, there is $63 \%$ chance that an experimenter is undecided about the lot sentencing. By comparing both sampling plans, we note that the plan under the classical statistics only has the decision of acceptance or rejection of the lot. The existing plan does not provide any information about the indeterminacy. So, the proposed sampling under the neutrosophic statistics is more effective and adequate under the uncertainty environment and this conclusion coincides with [21].

\section{Application of the proposed plan}

In this section, we present the application of the proposed sampling plan using the color STN displays data collected from the factory. According to [41] "Color STN displays are created by adding color filters to traditional monochrome. In color STN displays, each pixel is divided into R, G and B subpixels. In this study, the membrane thickness of each pixel is the quality characteristic". The color STN displays data of 55 values are reported in Table 3. For the given data, some statistics are shown in Table 4. From Table 4, we note that 37 items out-of 55 items belong to the non-defective group, 16 items out-of 55 belong to indeterminacy group and 2 items out-of 55 belong to failed items group (Table 5).

The proposed sampling plan for the given data is illustrated in the following steps.

Step-1: Select a random sample of size $n=55$ and let $c$ $=0$ from a lot of the product and obtain $x^{\mathrm{L}}=11,589.8$ and $x^{\mathrm{U}}=11,816.7$

Step-2: Compute mean $\bar{X}=\sum_{i=1}^{n} X_{i} / n=$ $11,715.2$ and standard deviation (SD) as $\mathrm{SD}=$ $\sqrt{\sum_{i=1}^{n}\left(X_{i}-X\right)^{2} / n-1}=49.21$.

Step-3: Set $a=[11,589.8,11,816.7]$ and compute $p_{\mathrm{ND}}=n_{\mathrm{ND}} / n=37 / 55 \approx 0.67, p_{\mathrm{I}}=n_{\mathrm{I}} / n=$ $16 / 55 \approx 0.29$ and $p_{\mathrm{D}}=n_{\mathrm{D}} / n=2 / 55 \approx 0.03$. So, $p=<\left[x^{\mathrm{L}}, x^{\mathrm{U}}\right],\left(p_{\mathrm{ND}}, p_{\mathrm{I}}, p_{\mathrm{D}}\right) \geq=<[11,589.8,11,816.7]$, $(0.67,0.29,0.03)$.

Step-4: The lot rejection, indeterminate, and acceptance probability is $L(p)=\{0.0000,1.0000,0.0000\}$. So, the lot acceptance probability for STN displays product is $0 \%$ while the lot indeterminacy is $100 \%$. It means, that a sample of size 5 items is selected from 16 indeterminate items.

\section{Conclusions}

A new neutrosophic fuzzy sampling plan using the neutrosophic statistics is presented in this paper. The proposed plan is more flexible than the sampling plans using classical statistics. The lot acceptance probability for various acceptance numbers and sample sizes are presented. The rules to find the probability of determinate, indeterminate and acceptance of a lot of the product given and some tables are given for the practical use. The existing sampling plan under the classical statistics has only the determined probability value and becomes the special case of the proposed plan when no certainty in the sample or in the population. The comparative study shows that the proposed plan is more effective and ade- 
Table 4 Distribution of color STN displays data of 55 values

\begin{tabular}{lllllll}
\hline$n$ & $\bar{X}$ & $\mathrm{SD}$ & {$\left[x^{\mathrm{L}}, x^{\mathrm{U}}\right]$} & $n_{\mathrm{T}}$ in $[\bar{X}-S, \bar{X}+S]$ & $\begin{array}{l}n_{\mathrm{I}} \text { in }[\bar{X}-3 S, \bar{X}-S] \text { and } \\
{[\bar{X}+S, \bar{X}+3 S]}\end{array}$ & $\begin{array}{l}n_{\mathrm{F}} \text { in }\left[x^{L}, \bar{X}-3 S\right] \text { and } \\
{\left[\bar{X}+3 S, x^{U}\right]}\end{array}$ \\
\hline 55 & $11,715.2$ & 49.21 & {$[11,589.8,11,816.7]$} & 37 & 16 & 2 \\
\hline
\end{tabular}

Table 5 Data on color STN displays

\begin{tabular}{llllll}
\hline $11,816.7$ & $11,710.1$ & $11,722.6$ & $11,744.1$ & $11,681.1$ & $11,728.4$ \\
$11,712.6$ & $11,775.2$ & $11,743.3$ & $11,786.1$ & $11,760.6$ & $11,723.6$ \\
$11,721.7$ & 11,698 & $11,695.9$ & $11,726.4$ & $11,797.2$ & $11,773.1$ \\
$11,769.1$ & $11,800.8$ & $11,780.7$ & $11,670.9$ & $11,692.3$ & $11,666.2$ \\
$11,755.2$ & $11,712.7$ & $11,775.5$ & $11,731.2$ & $11,625.6$ & $11,757.5$ \\
$11,674.7$ & $11,729.2$ & $11,681.3$ & $11,636.4$ & $11,682.1$ & $11,667.9$ \\
$11,722.9$ & $11,655.3$ & $11,700.2$ & $11,754.2$ & $11,769.9$ & $11,705.9$ \\
$11,589.8$ & $11,738.4$ & $11,745.4$ & $11,727.7$ & $11,664.3$ & $11,647.2$ \\
11,755 & $11,671.8$ & $11,705.8$ & $11,664.2$ & 11,677 & $11,680.5$ \\
$11,633.6$ & & & & & \\
\hline
\end{tabular}

quate than the sampling plan using classical statistics under the uncertainty environment. The proposed sampling plan can only be used when data are discrete. It is recommended that the proposed plan should apply for the inspection of lot of products under the uncertainty environment. The proposed sampling plan using the cost model can be considered as future research. The proposed plan under the time truncated life test can be considered as future research.

Acknowledgements The author is deeply thankful to the editor and reviewers for their valuable suggestions to improve the quality of the manuscript.

\section{Compliance with ethical standards}

Conflict of interest The authors declare that they have no conflict of interests.

Data availability statement The data underlying the results presented in the study are available within the manuscript.

Open Access This article is distributed under the terms of the Creative Commons Attribution 4.0 International License (http://creativecomm ons.org/licenses/by/4.0/), which permits unrestricted use, distribution, and reproduction in any medium, provided you give appropriate credit to the original author(s) and the source, provide a link to the Creative Commons license, and indicate if changes were made.

\section{References}

1. Montgomery DC (2007) Introduction to statistical quality control. Wiley, New York
2. Cheng S-R, Hsu B-M, Shu M-H (2007) Fuzzy testing and selecting better processes performance. Ind Manag Data Syst 107(6):862-881

3. Jamkhaneh EB, Sadeghpour-Gildeh B, Yari G (2011) Inspection error and its effects on single sampling plans with fuzzy parameters. Struct Multidiscip Optim 43(4):555-560

4. Sadeghpour Gildeh B, Baloui Jamkhaneh E, Yari G (2011) Acceptance single sampling plan with fuzzy parameter. Iran J Fuzzy Syst $8(2): 47-55$

5. Jamkhaneh EB, Gildeh BS (2012) Acceptance double sampling plan using fuzzy poisson distribution. World Appl Sci J 16(11):1578-1588

6. Turanoğlu E, Kaya İ, Kahraman C (2012) Fuzzy acceptance sampling and characteristic curves. Int J Comput Intell Syst 5(1):13-29

7. Jamkhaneh EB, Gildeh BS (2013) Sequential sampling plan using fuzzy SPRT. J Intell Fuzzy Syst 25(3):785-791

8. Divya P (2012) Quality interval acceptance single sampling plan with fuzzy parameter using poisson distribution. Int $\mathrm{J}$ Adv Res Technol 1(3):115-125

9. Venkateh A, Elango S (2014) Acceptance sampling for the influence of TRH using crisp and fuzzy gamma distribution. Aryabhatta J Math Inform 6(1):119-124

10. Kahraman C, Bekar ET, Senvar O (2016) A fuzzy design of single and double acceptance sampling plans. In: Kahraman C, Yanik S (eds) Intelligent decision making in quality management. Springer, Cham, pp 179-211

11. Afshari R, Gildeh BS (2017) Construction of fuzzy multiple deferred state sampling plan. In: Fuzzy systems association and 9th international conference on soft computing and intelligent systems (IFSA-SCIS), 2017 joint 17th World Congress of International. IEEE

12. Afshari R, Sadeghpour Gildeh B, Sarmad M (2017) Fuzzy multiple deferred state attribute sampling plan in the presence of inspection errors. J Intell Fuzzy Syst 33(1):503-514

13. Afshari R, Gildeh BS, Sarmad M (2017) Multiple deferred state sampling plan with fuzzy parameter. Int J Fuzzy Syst 20:1-9

14. Elango S, Venkatesh A, Sivakumar G (2017) A fuzzy mathematical analysis for the effect of TRH using acceptance sampling plans. Int J Pure Appl Math 117:1-7

15. Smarandache F (2010) Neutrosophic logic-a generalization of the intuitionistic fuzzy logic. In: Multispace \& multistructure. Neutrosophic transdisciplinarity (100 collected papers of science), vol 4 , p 396

16. Majumdar P (2015) Neutrosophic sets and its applications to decision making. In: Acharjya D, Dehuri S, Sanyal S (eds) Computational intelligence for big data analysis. Springer, Cham, pp 97-115

17. Wang $\mathrm{H}$ et al (2005) Single valued neutrosophic sets. In: Proceedings of 10th 476 international conference on fuzzy theory and technology. Citeseer

18. Aiwu Z, Jianguo D, Hongjun G (2015) Interval valued neutrosophic sets and multi-attribute decision-making based on generalized weighted aggregation operator. J Intell Fuzzy Syst 29(6):2697-2706

19. Smarandache F (2014) Introduction to neutrosophic statistics. Infinite Study, Ann Arbor 
20. Chen J, Ye J, Du S (2017) Scale effect and anisotropy analyzed for neutrosophic numbers of rock joint roughness coefficient based on neutrosophic statistics. Symmetry 9(10):208

21. Chen J et al (2017) Expressions of rock joint roughness coefficient using neutrosophic interval statistical numbers. Symmetry 9(7):123

22. Abdel-Basset $\mathrm{M}$ et al (2017) Multi-criteria group decision making based on neutrosophic analytic hierarchy process. J Intell Fuzzy Syst 33(6):4055-4066

23. Abdel-Basset M, Mohamed M, Smarandache F (2018) An extension of neutrosophic AHP-SWOT analysis for strategic planning and decision-making. Symmetry 10(4):116

24. Abdel-Basset $\mathrm{M}$ et al (2018) Neutrosophic association rule mining algorithm for big data analysis. Symmetry 10(4):106

25. Abdel-Basset M, Mohamed M, Smarandache F (2018) A hybrid neutrosophic group ANP-TOPSIS framework for supplier selection problems. Symmetry 10(6):226

26. Abdel-Basset M, Mohamed M, Chang V (2018) NMCDA: a framework for evaluating cloud computing services. Future Gener Comput Syst 86:12-29

27. Abdel-Basset $\mathrm{M}$ et al (2018) A group decision making framework based on neutrosophic VIKOR approach for e-government website evaluation. J Intell Fuzzy Syst 34(6):4213-4224

28. Abdel-Basset M, Mohamed M (2018) The role of single valued neutrosophic sets and rough sets in smart city: imperfect and incomplete information systems. Measurement 124:47-55

29. Abdel-Basset M et al (2018) A hybrid approach of neutrosophic sets and DEMATEL method for developing supplier selection criteria. Des Autom Embed Syst. https://doi.org/10.1007/s10617-0189203-6

30. Abdel-Basset M, Gunasekaran M, Mohamed M et al (2018) A novel method for solving the fully neutrosophic linear programming problems. Neural Comput Appl. https://doi.org/10.1007/s00521018-3404-6

31. Abdel-Basset $\mathrm{M}$ et al (2018) Three-way decisions based on neutrosophic sets and AHP-QFD framework for supplier selection problem. Future Gener Comput Syst 89:19-30
32. Aslam M (2018) A new sampling plan using neutrosophic process loss consideration. Symmetry 10(5):132

33. Aslam M, Arif O (2018) Testing of grouped product for the Weibull distribution using neutrosophic statistics. Symmetry 10(9):403

34. Aslam M, Raza MA (2018) Design of new sampling plans for multiple manufacturing lines under uncertainty. Int J Fuzzy Syst. https://doi.org/10.1007/s40815-018-0560-x

35. Aslam M (2018) Design of sampling plan for exponential distribution under neutrosophic statistical interval method. IEEE Access 6:64153-64158

36. Broumi $\mathrm{S}$ et al (2017) Shortest path problem under bipolar neutrosphic setting. Appl Mech Mater 859:59-66

37. Broumi $S$ et al (2018) Shortest path problem under interval valued neutrosophic setting. J Fundam Appl Sci 10(4S):168-174

38. Broumi S et al (2016) Application of Dijkstra algorithm for solving interval valued neutrosophic shortest path problem. In: 2016 IEEE symposium series on computational intelligence (SSCI). IEEE

39. Broumi $\mathrm{S}$ et al (2017) Computing operational matrices in neutrosophic environments: a Matlab toolbox. Neutrosophic Sets Syst 18:58-66

40. Broumi S et al (2017) A Matlab toolbox for interval valued neutrosophic matrices for computer applications. Uluslararası Yönetim Bilişim Sistemleri ve Bilgisayar Bilimleri Dergisi 1(1):1-21

41. Aslam $M$ et al (2012) Two-stage variables acceptance sampling plans using process loss functions. Commun Stat Theory Methods 41(20):3633-3647

Publisher's Note Springer Nature remains neutral with regard to jurisdictional claims in published maps and institutional affiliations. 